\title{
Research priorities for grassland science: the need of long term integrated experiments networks
}

\section{G. Lemaire}

INRA, Unite d'Ecophysiologie des Plantes Fourragères. 86600, Lusignan, France.

\begin{abstract}
Grasslands have to be considered not only as a mean for providing foods for domestic herbivore but also as an important biome of terrestrial biosphere. This function of grasslands as an active component of our environment requires specific studies on the role and impact of this ecosystem on soil erosion and soil quality, quality and quantity of water resources, atmosphere composition and greenhouse gas emission or sequestration, biodiversity dynamics at different scales from field plot to landscape. All these functions have to be evaluated in conjunction with the function of providing animal products for increasing human population. So multifunctionality of grasslands become a new paradigm for grassland science. Environmental and biodiversity outputs require long term studies, being the long term retro-active processes within soil, vegetation and micro-organism communities in relation to changes in management programme. So grassland science needs to carry on long term integrated experimentation for studying all the environmental outputs and ecological services associated to grassland management systems.
\end{abstract}

Key Words: agro-ecology, environment, grassland science, research priorities, tertiary education

\section{Introduction}

The grassland biome covers $36 \%$ of the earth's surface (Shantz, 1954), approximately equivalent to the forest area and the area of arable cultivation. It is important for research objectives to consider two types of grasslands, (i) the climaticallydetermined grasslands in areas where water availability is not enough to support forests (Lauenroth, 1979), and (ii) the anthropogenicallydetermined grasslands located in most of the temperate regions where the potential vegetation is forest and where herbaceous vegetation is maintained by domestic herbivore exploitation. Within this second type of grassland it is possible to distinguish long term naturalized grasslands from cultivated grasslands in cropping areas. The first is composed of semi-natural vegetation maintained in semi-equilibrium by given management systems such as pasture and hay making while the second are based on sown grassland in rotation with arable cropping systems. All these type of grasslands play an important role in the dynamics of atmosphere, hydrosphere and soil interactions driving global changes and environmental hazards, or adjusting to them. Grasslands therefore play a vital role in the structure and functioning of the overall landscape. They also contribute to effects on agronomic, social, environmental and economic activities at national, regional and catchment scales.

Nowadays, the objective of grassland science cannot be only to contribute to food production by optimizing vegetation - animal interactions in order to provide alimentary resources for domestic herbivore. Other objectives as contributions of grassland agro-eco-systems to and their response to global warming and other environmental problems at global or local scale, the roles of grassland area to landscape functioning in term of quantity and quality of water resources and in term of biodiversity dynamics have to be also clearly identified in research programmes. Developments in agricultural technology in the second half of the 20th Century resulted in impressive improvements in the technical efficiency of food production in specific sectors, but also contributed to serious declines in the stability of the world's land, water, environmental and biological resources (Dahlberg, 1979; van der Meer \& van 
der Putten, 1995). At the same time, there has been much less positive impact on the productivity of small-scale mixed farming systems in developing countries (Serageldin, 2001). So either at the world scale and at regional or local scale it is necessary for grassland research to consider simultaneously different and contradictory objectives such as providing increasing quantity of foods to an increasing human population and in the same time contributing to reduce environmental hazards and to increase ecological services.

\section{Grassland as an agro-ecosystem}

Grassland ecosystems are composed of inseparable and interactive components: (i) a vegetation community or communities together with a varied population of herbivores, (ii) the physical and chemical components of the soil, (iii) a diverse soil microbial community and microfauna.

All these three components of the ecosystem are in interaction through feed back loops operating at different time scales. They are subjected to herbivory (above and below ground) and mineral recycling through herbivore ingestion and excretion or through additions of fertilizers and manures. Vegetation dynamics is dependant upon the $\mathrm{C}, \mathrm{N}$ and other mineral cycles, but changes in vegetation modify in return biogeochemical processes. Many such systems contain legumes which contribute to cycling of $\mathrm{N}$ by biologically fixing $\mathrm{N}_{2}$.

These ecosystems are important for the quality of atmosphere and hydrosphere, for biodiversity, and as a major part of the ecology of the landscape. Grassland ecosystems have to be managed with multi-purpose objectives corresponding to the different functions assigned to grasslands: environment, biodiversity, landscape ecology, and agricultural production with socio-economic outputs (Dahlberg, 1979; 1986).

In most of the European countries large land areas were formerly used in mixed farming systems where grasslands and crops interacted intimately, either spatially by exchanges of foods for animals and organic matter returns, or temporally through ley-crops rotations. Such a system provided sustainable farming in agronomic terms by insuring long term soil quality

๑ 2007 Sociedade Brasileira de Zootecnia preservation, and also in economic terms by insuring diversification of incomes for farmers. The requirement to increase food production, because of increasing world population and political instability, much increased the emphasis on production from grasslands (Wahlen, 1952; Whyte, 1960), and the increased use of fertilisers and technical chemicals associated in some areas with the expansion of silage maize cultivation reduced the importance of grassland in mixed farming systems. Emphasis on technical efficiency led to increasing specialisation in research and production, with spectacular effects on the productivity of grassland systems (Humphreys, 1997), but resulted in the progressive de-coupling of research on alternative or complementary land uses, on the production and conservation elements of grassland use, and even of soil, plant and animal research in grassland studies (Wilkins, 2000). The resulting simplification and intensification of agricultural practice gave rise to problems of pollution, waste disposal and reduced biodiversity in the countryside. These are now major elements of concern in land use research.

In large parts of Europe intensification of cropping and dairy systems associated with the high prices for products has led to a specialisation of farms with the most fertile cultivated lands devoted to cereal cropping, and less fertile regions with smaller farm units devoted to intensive animal production. Each of these two systems now faces serious environmental problems, and this specialisation of land use at landscape level cannot be maintained. Because the specialisation of farming itself may be inescapable, new strategies of mixed land use by association of farm units specialised respectively in crop and animal production have to be promoted at landscape and regional levels in order to maintain a patchwork of cropping and grassland systems which contribute to a more sustainable agriculture. So new scientific questions emerge, concerning: (i) the roles for grassland at landscape level for ecological, agronomic and environmental objectives, (ii) the definition of types of grassland vegetation and management systems for optimising these roles, and (iii) the appropriate siting of grasslands within landscapes or catchments. These questions have never been addressed in the past, where research studies were 
concentrated upon either the field or the farm, but not at the landscape or territory level.

The concept of multi-functionality of agriculture provides a new framework for all disciplines in the sector of grassland research (Hervieu, 2002). Scientific objectives, methods of investigation and models have to be reconsidered with the aim of producing an integrative approach at a range of scales (field plot, farm, landscape, territory...) where the different functions can be evaluated. The multiple functions of grassland also demand a genuinely inter-disciplinary approach to research. To achieve such objectives it is necessary to produce integrated knowledge, new concepts and new tools at the different levels of organisation of grassland agro-ecosystems: (i) the field plot where the basic biogeochemical processes are acting, (ii) the farming system where coherent management procedures are combined, (iii) the landscape where multi-functionality, interactions between different land uses and overall impact can be evaluated and (iv) the region/ nation state where socio-economic and political factors become important. Ormerod et al. (2003) emphasise the important role of ecologists in dealing with major agro-environmental questions, but the issues are much broader than this.

\subsection{The role of grassland for regulating biogeochemical cycles, environmental fluxes and biodiversity at local scale.}

The world's grasslands play an important role in regulation of the $\mathrm{C}$ cycle by storing ca. $15 \%$ of the global organic C (Tate \& Ross, 1997). The mean annual primary production of grassland is similar to that of forest (Körner, 1999), and given that more than two thirds of the annual grassland biomass production is allocated to below ground structures, accumulation of deep soil organic matter layers makes an important contribution to $\mathrm{C}$ sequestration in most grassland ecosystems (Körner, 2002). The role of grassland in regulating the $\mathrm{N}$ cycle is more complex because grazing animals recover, on average, only $7 \%$ of the $\mathrm{N}$ supply (Grignani \& Laidlaw 2002). Nitrogen fluxes in grassland systems contribute directly to three environmental concerns: nitrate leaching, volatilization of ammonia, and nitrous oxide emissions. Research to relate operational management decisions in grassland systems directly to their consequences to environmental fluxes have produced new methods and new concepts (Jarvis 1999), but have not yet permitted an integrated view of the dynamics of the grassland ecosystem because: (i) the individual fluxes (nitrate leaching, $\mathrm{N}_{2} \mathrm{O}$ and $\mathrm{NH}_{3}$ emission, $\mathrm{CO}_{2}$ sequestration or emission...) too often have been studied separately despite their great interdependency, and (ii) the characteristic turnover times of the different processes involved within the system are not well known despite recent advances in stable isotope methodologies (Murphy et al., 2003). Most of these fluxes are related to soil organic matter (SOM) dynamics through soil microbial activities which couple the different processes. Moreover, the residence times of $\mathrm{C}$ and $\mathrm{N}$ within the different chemical and physical compartments of SOM are relatively long, varying from 10 to more than 100 years (Balesdent \& Mariotti, 1996). In consequence, some of the environmental outputs observed today could be the delayed consequences of changes in land use and management that occurred several years or decades ago. Similarly, changes in land use and management systems for restoring environment and biodiversity require more precise information on the time responses of the whole system: vegetation, animal, soil and microbial communities. The key scientific knowledge required is a functional and biochemical identification of the different fractions of the soil organic matter. To understand the process of SOM stabilisation, it is necessary to characterise the main biochemical compounds interacting with the soil matrix, and how $\mathrm{C}$ and $\mathrm{N}$ are protected from microbial activities. Questions on the storage of $\mathrm{C}$ in grassland soils and the equilibrium between $\mathrm{C}$ sequestration and $\mathrm{C}$ mineralisation are of high relevance for global change issues (Soussana et $a l ., 2004)$. It is difficult to compare $\mathrm{CO}_{2}$ links in grassland and forest biomes, because there is little information on the long term dynamics of SOM in grasslands. Modelling is the only tool for predicting long term evolution of $\mathrm{C}$ in soils, but for a realistic and mechanistic representation of the dynamics of the SOM system it is necessary to invest more deeply in characterising the different functional compartments by their molecular signature (Poirier et al., 2000; Rumpel et al., 2004). There is also little information on $\mathrm{C}$

\footnotetext{
๑ 2007 Sociedade Brasileira de Zootecnia
} 
sequestration in deep soil horizons. The great majority of studies concern only the storage of $\mathrm{N}$ within the $0-30 \mathrm{~cm}$ soil layer, but, as demonstrated by Rumpel et al. (2002), 50\% of C can be stored within deeper horizons with a higher residence time than for $\mathrm{C}$ stored in upper layers where microbial activity is high. This demonstrates that our knowledge on SOM and C-N cycles in grassland soil is fragmented. Due to the importance of grasslands as one of the largest biomes on the planet increase in basic knowledge on SOM long term dynamics must be placed at a high priority for grassland science.

Predicting plant species and community responses to grazing management is difficult (Herben \& Huber-Sannwald, 2002). Diversity of grassland vegetation has long been described in terms of species number and botanical composition. Species-specific differences in life cycle phenology and growth form explain a part of this diversity (Sackville-Hamilton \& Harper, 1989). More recently attempts have been made to explain diversity of grassland vegetation by functional traits (Lavorel \& Garnier, 2002), either at leaf level or at root level. The advantage of such a functional approach in comparison to the botanical approach is to link vegetation diversity to the different functions the plants have to play within the ecosystem: primary production, litter quality and decomposition, competition for light and for soil resources, and interactions with herbivores. So different species, independently of their position within the phylogeny, may have similar functional traits, either in terms of ecosystem effects or in terms of response to change, allowing them to be re-arranged in similar functional groups. The interactions between plants and soil micro-organisms may critically affect plant growth, plant-plant interactions and potentially plant community composition and structure (Clay, 1990). In turn, changes in plant community composition could affect microbial communities and then the soil organic matter dynamics with more or less long term feed back (McGaig et al., 1999). So the analysis of vegetation dynamics in term of functional groups appears to be a very powerful tool for linking changes in vegetation with biogeochemical cycles and vice versa, and also for studying effects of herbivore behaviour on vegetation dynamics and

${ }^{\circledR} 2007$ Sociedade Brasileira de Zootecnia vice versa. Spatial variations in patterns of grazing and excretion, and spatio-temporal changes in abiotic and biotic environments, affect the spatial pattern and structure of vegetation (Watkinson \& Ormerod, 2001; Garcia et al., 2004). So studies in vegetation dynamics need to include information on temporal and spatial heterogeneity which is a dynamic component of the grazing ecosystem.

\subsection{The need for integrated long term experiments}

For all the reasons discussed above, it appears necessary to develop integrated inter-disciplinary programmes based on networks of long term experiments to complement and extend processbased research. With this approach:

- a wide range of grassland ecosystems (climate, soil, vegetation) would be investigated;

- contrasting managements would be applied as perturbations for long term observation of divergent evolutionary trajectories;

- time course for evolution of relevant state variables for vegetation, soil and populations of organisms would be monitored;

- plant-herbivore interactions and their consequences to biogeochemical cycles and vegetation dynamics would be analysed;

- environmental fluxes from and to the atmosphere and to the hydrosphere would be regularly estimated and related to changes in state variables in relation to global changes;

- key processes and interactions between compartments of the systems would be evaluated.

Such a network should be considered as a large scale field laboratory providing fundamental, mechanistic information on system function and resilience. To do this will require us to undertake key core measurements such as (i) identifying and characterizing the compartments of the soil organic matter playing a key role, (ii) quantifying some of the key internal fluxes and to monitor at the boundaries of the system fluxes towards atmosphere and hydrosphere, (iii) investigating the functional role of plant, microbial and soil fauna diversity with the aim of characterising the response of the whole system to the disturbance regime induced by contrasted management over 
the long term, (iv) simulating the long term evolution of the system under climate change scenarios

The outcome of such a research programme must be a common integrated data base and information system allowing exchanges and communication between different research teams of different disciplines. Moreover, theoretical frameworks and simulation models to explain the evolution of each of the main agro-ecosystem in relation to management should be developed. The information and knowledge gained from this research will underpin scenario simulations to evaluate environmental hazards and impacts on functional biodiversity resulting from a wide range of contrasting land use and management systems. Ultimately, the scientific and technological outcomes would of great value in informing local, national and international policy makers of options available for developing sustainable farming and land use systems which are both environmentally benign and economically viable.

The objective should therefore be to set up a network of long-term experimental platforms with woodlands, permanent grasslands, mixed grassland-cropping systems and arable cropping systems. Sites which are in transition from $e g$ longterm arable to permanent grassland or from grassland to woodland should also be included. The network would comprise, predominantly, existing long-term experiments but may require the establishment of a limited number of new experiments. Each of these experimental platforms should have its own scientific objectives, experimental design and monitoring and measurement technology according to its local site specific conditions. Nevertheless a common core of investigation and method should be established.

Whatever the agro-ecosystem, the site soil organic matter dynamics will play a central role in regulating the different environmental fluxes. Moreover, the SOM represents the memory of the system because this component of the soil has a long residence time (from 10 to more than 100 years). Therefore, it is necessary to identify the different compartments or pools within SOM and to characterize their functional properties using common protocols and analytical techniques. The different experimental platforms should be sampled regularly in order to analyse the dynamics of change of SOM quantity and quality and the changes in microbial communities and their activities under controlled and known conditions. A collection of core samples should be archived, such that further analyses can be made as new scientific questions arise and as new analytical techniques are developed in the future. The experimental plots must be large enough to (i) minimize the effects of materials between treatments, (ii) allow periodic sampling of soil (iii) establish micro-plots or sampling areas within existing treatments in order to hypothesis test short term process dynamics and to compare different soil-vegetation systems whose state variables may have changed significantly according to the treatment and (iv) allow for later division of plots to test alternative treatments and/or management strategies.

Thus, this network of research platforms should become an attractive resource for different research teams specialised in different disciplines to carry on their own research within a context where the historical management and evolution of the whole system have been carefully monitored. Hence a pluri-disciplinary approach or even an inter-disciplinary approach to the functioning of the agro-ecosystems would be possible through the interactions between the different research teams and between the different experimental sites would be encouraged. Such a network in Europe should greatly improve scientific exchange and stimulation of new scientifically sound concepts between the different countries and also should also enhance postgraduate development in a more international context. Such a network in Europe could ultimately become a partner of the Long Term Ecological Research network previously established in USA, and then could play an important scientific role at the global level.

The outcome of such research should be common integrated data bases and theoretical frameworks to explain the long term evolution of grassland systems subjected to contrasted management programmes. A modelling approach would be necessary for integrating information and knowledge gained from this research. This would underpin scenario simulations to evaluate environmental and agricultural issues in terms of risks or benefits resulting from a range of

๑ 2007 Sociedade Brasileira de Zootecnia 
management systems. The scientific and technological outcomes will be crucial in informing local, national and international policy makers on the role, impact and management of grassland systems for sustainable land use.

\section{Grassland at farm and landscape scale: environmental and ecological analysis and socio-economic perspectives}

The approach discussed above is built on process-based research and it cannot take into account all the diversity of management programmes that grassland areas are subjected to. Moreover, the scale of investigation is the field plot, and then other spatial scale such as farm or landscape or catchment where other processes are operating are not taken into account. This "What if..." approach is not sufficient for conceiving and evaluating new management programmes dealing with environment, biodiversity and socioeconomic issues at larger scale. It is necessary to complement this kind of research by developing an integrated network at the level of both animal production systems and mixed grazing and cropping systems to investigate the role of different land-management programmes in resource conservation and agricultural production. The question we have to ask at this level of investigation is "What is necessary for...?" That is the reverse question of the preceding one. To answer this question for a series of different case studies requires the creation of new generic methodologies for conceiving and evaluating new agro-ecosystems which can satisfy multiple objectives. It is then necessary here to account for human and society dimension of the system being managed, and not only on their natural processes. The achievement of compromise between the different goals (animal production, socio-economic benefits, environmental risk, biodiversity conservation or other public goods like amenity of landscape) depends on the different stakeholders and social groups involved, and several scenarios have to be investigated to provide decision support to policy makers. This suggests the need for a modelling approach for the simulation and evaluation of virtual systems in order to prospect a large spectrum of possibilities and to select optimum compromises between contradictory objectives.
At this level of investigation grasslands have to be considered as components of a land use system. This may be a pure grassland area like the Savanna in Africa, the Pampa and Campos in South America or the Steppe in Asia, but in most other areas in the world grassland is only a part of the land cover at the scale of landscape, and this ecosystem interacts spatially or temporally either with forest or shrub vegetation or with cropping areas. In these situations landscapes have to be explicitly described as a mosaic of soil cover with spatially distributed management programmes. The functioning of such a territorial entity can be analysed through:

- the integrated environmental fluxes at the boundaries of the system to the atmosphere and hydrosphere taking into account the spatial interactions between the different agro-ecosystems;

- biodiversity at different levels of organisation within the territory and for different populations or communities of plants, insects, birds and mammals (Wallis De Vries, 2002);

- the landscape value from a cultural and heritage point of view (Mormont, 2002).

The intensification of agriculture of NorthWest Europe with the disappearance of most of the grasslands from cereal production regions was accompanied by the extinction of large number of plants, insects, birds and micro-mammals. Grasslands represent an important habitat and a source of food for several protected bird species (Inchausti \& Bretagnolle, 2005; Bretagnolle \& Inchausti, 2005). Such a role of grassland in biodiversity conservation can only be analysed at landscape level, and must necessarily take into account the socio-economic forces which determine the land use system and its evolution.

Such an integrated and multidisciplinary approach should help to define some options in land use and management systems to be promoted at regional scale for optimising the multifunctionality of agriculture. But this approach does not take into account the potential for socioeconomic resistance to change, which needs to be identified in order to allow some evolution in land use and management systems in the direction of a more sustainable agriculture and rural economy. 
For this purpose the landscape has to be considered as an assembly of farmers and farm units which respond individually to their own socio-economic constraints in relation to their own goals. These farmers have individually good reasons for doing that they do in their farms, and not doing that the environmentalist want they do. So these reasons have to be analysed ans studied if we want change agriculture to a more sustainable way. Multifunctionality of agriculture has to meet human demands for rural development, and socioeconomic researchers have to identify and to make explicit the contradictions between the socioeconomic goals of farmers and the environmental or ecological goals of the other components of society. The whole process would be aided by progress in methodology for putting a financial value on the environmental and social aspects of multifunctionality. This would facilitate the identification of optimised land use and management systems, targeting policy for sustainable agriculture, and determination of the role of grassland in such an objective.

\section{Conclusion}

Grasslands have to be considered at world level as biome as important as forest for global environment of the earth in relation with global changes. For that, grassland has to be considered not only as a mean for producing food for domestic herbivores to ensure increasing food demand from increasing human population, but also as a functional component of the biosphere for regulating all the bio-geochemical cycles and the dynamics of biodiversity. Multifunctionality is a new paradigm for grassland science. It requires multi-disciplinary research and multi-scale approaches. If animal production related to grassland management is a relatively short term issue, environment and biodiversity purposes require long term observation and experimentation to provide significant results. So grassland science needs to organize networks of long term multidisciplinary experimental plat-forms at national or at international scale, in order to monitor and compute all agronomical, environmental and ecological outputs. Such a network requires a more integrated organisation of grassland research either at national and international level.

\section{Literature citad}

BALESDENT, J.; MARIOTTI, A. Measurement of soil organic matter turnover using $13 \mathrm{C}$ natural abundance. In: Boutton, T.W., Yamasaki, S.I. (Eds.), Mass Spectrometry of Soils, Marcel Dekker, New York, pp.83-111, 1996.

BRETAGNOLLE, V.; INCHAUSTI, P. Modelling population reinforcement at large spatial scale as a conservation strategy for the declining Little Busard (Tetrax tetrax) in agricultural habitats. Animal conservation (in press), 2005.

CLAY, K. The impact of parasitic and mutualistic fungi on competitive interactions among plants. In: Grace, J.B., Tilman, D. (Eds.), Perspectives on Plant Competition. Academic Press, San Diego, pp. 391-413, 1990.

DAHLBERG, K.A. Beyond the Green Revolution. The Ecology and Politics of Global Agricultural Development. Plenum Press, New York. 1979.

DAHLBERG, K.A. New Dimensions for Agricultural Research. Neglected Dimensions and Emerging Alternatives. Rowman and Allanheld, Tatowa, New Jersey. 1986.

GARCIA, F.; CARRÈRE, P.; SOUSSANA, J.F. et al. Characterisation by fractal analysis of foraging paths of ewes grazing heterogeneous swards. Appl. Anim. Behav. Sci., 2004.

GRIGNANI, C.; LAIDLAW, A.S. Nitrogen economy on grasslands and annual forage crops: control of environmental impact. In: Durand, J.L., Emile, J.C. , Huyghe, C., Lemaire, G., (Eds.), Multifunction Grasslands, Quality Forages, Animal Products and Landscapes. Proceeding of the 19th general meeting of the European Grassland Federation, British Grassland Society, Reading UK, pp 625-633, 2002.

HERBEN, T.; HUBER-SANNWALD, E. Effects of management on species richness of grasslands: sward scale processes lead to large-scale patterns. In: Durand, J.L., Emile, J.C., Huyghe, C., Lemaire, G., (Eds.), Multifunction Grasslands, Quality Forages, Animal Products and Landscapes. Proceeding of the $19^{\text {th }}$ general meeting of the European Grassland Federation, British Grassland Society, Reading UK, pp. 635-643, 2002.

HERVIEU, B. Multi-functionality: a conceptual framework for a new organisation of research and development on grassland and livestock systems. In: Durand, J.L.; Emile, J.C.; Huyghe, C.; Lemaire, G. (Eds.). Multifunction Grasslands, Quality Forages, Animal Products and Landscapes. Proceedings of the 19th general meeting of the European Grassland Federation, British Grassland Society, Reading UK, pp. 1-2, 2002.

HUMPHREYS, L.R. The Evolving Science of Grassland Improvement. Cambridge University Press, Cambridge, UK, 1997.

INCHAUSTI, P., BRETAGNOLLE, V. Predicting short-term extinction risk for the declining Little Busard (Tetrax tetrax) in agriculture areas. Biol. Conserv. (in press), 2005.

JARVIS, S.C. Accounting for nutrients in grassland: Challenges and needs. In: Corall A.J. (Ed.), Accounting for nutrients: A challenge for grassland farmers in the $21^{\text {st }}$ century. Occasional Symposium No 33, British Grassland Society, pp.3-12, 1999.

KÖRNER, C. Grassland in a $\mathrm{CO}_{2}$-enriched world. In: Durand, J.L.; Emile, J.C.; Huyghe, C.; Lemaire, G. (Eds.). Multifunction Grasslands, Quality Forages, Animal Products and Landscapes. Proceedings of the 19th general meeting of the European Grassland Federation, British Grassland Society, Reading, UK. pp. 611-624, 2002.

LAUENROTH, W.K. Grassland primary production: North American Grasslands in perspective. In: French, N.R. (Ed.). Perspectives in Grassland Ecology. Ecological Studies. Springer-verlag, New York, Heidelberg,pp.3-24, 1979.

() 2007 Sociedade Brasileira de Zootecnia 
LAVOREL, S.; GARNIER, E. Predicting changes in community composition and ecosystem functioning from plant traits: revisiting the Holy Grail. Funct. Ecol., v.16, p.545-556, 2002.

MCGAIG A.E.; GLOVER A.; PROSSER J.I. Molecular analysis of bacterial community structure and diversity in unimproved and improved upland grass pasture. Appl. Env. Microbiol., v. 65, p.1721-1730, 1999.

MORMONT, M. What does grassland represent? In: Durand, J.L.; Emile, J.C.; Huyghe, C.; Lemaire, G. (Eds). Multifunction Grasslands, Quality Forages, Animal Products and Landscapes. Proceedings of the 19th general meeting of the European Grassland Federation, British Grassland Society, Reading. UK. pp. 867-873, 2002.

MURPHY, D.V.; RECOUS, S.; STOCKDALE, E.A. et al. Gross nitrogen fluxes in soil: theory, measurement and application of $15 \mathrm{~N}$ pool dilution techniques. Adv. Agron., v.79, p.69-119, 2003.

ORMEROD, S.J.; MARSHALL, E.J.P.; KERBY, G. et al. Meeting the Ecological Challenges of Agricultural Change: Editors' Introduction. J. Appl. Ecol., v.40, p.939-946, 2003.

POIRIER, N.; DERENNE, S.; ROUZAUD, J.N. et al. Chemical structure and sources of the macromolecular resistant, organic fraction isolated from a forest soil (Lacadee, south-west France). Org.Geochem., v.31, p.813827,2000

RUMPEL, C.; EUSTERHUES, K.; KÖGEL-KNABNER, I. Location and chemical composition of stabilized organic carbon in topsoil and subsoil horizons of two acid forest soils. Soil Biol. Biochem., v.36, p.177-190, 2004.

RUMPEL, C.; KÖGEL-KNABNER, I.; BRUHN, F. Vertical distribution, age, and chemical composition of organic carbon in two forest soils of different pedogenesis. Org. Geochem., v. 33, p.1131-1142, 2002.

SACKVILLE-HAMILTON, N.R.; HARPER, J.L. The dynamics of Trifolium repens in a permanent pasture. I-
The population of leaves and nodes per shoot axis. Proc. R. Soc. Lond. Series B, v. 237, p. 133-173, 1989.

SERAGELDIN, J. Changing agendas for agricultural research. In: Alston, J.M.; Pardey, P.G.; Taylor, M.J. (Eds.) Agricultural Science Policy. Changing Global Agendas. International Food Policy Research Institute, Washington, D.C. pp. 13-20, 2001.

SHANTZ, H. The place of grasslands in the earth's cover of vegetation. Ecology, v.35, p.142-145, 1954

SOUSSANA, J.F.; LOISEAU, P.; VUICHARD, N. et al. Carbon cycling and sequestration opportunities in temperate grasslands. Soil Use Manage., v.20, p.219-230, 2004.

TATE, K.R.; ROSS, D.J. Elevated $\mathrm{CO}_{2}$ and moisture effects on soil carbon storage and cycling in temperate grasslands. Glob. chang. Biol., v.3, p.225-235, 1997.

VAN DER MEER, H.G.; VAN DER PUTTEN, A.H.J. Reduction of nutrient emissions from ruminant livestock farms. In: Pollott, G.E. (Ed.), Grassland Into the 21st Century: Challenges and Opportunities. Occasional Symposium No. 29, British Grassland Society, Harrogate. pp. 118-134, 1995.

WALLIS DE VRIES, M.F. Options for the conservation of wet grasslands in relation to spatial scale and habitat quality. In: Durand, J.L.; Emile, J.C.; Huyghe, C.; Lemaire, G. (Eds.). Multi-function Grasslands, Quality Forages, Animal Products and Landscapes. Proceedings of the 19th general meeting of the European Grassland Federation, British Grassland Society, Reading. UK. pp. 883-892, 2002.

WATKINSON, A.R.; ORMEROD, S.J. Grasslands, grazing and biodiversity: Editor's introduction. J.Appl. Ecol., v.38, p.233-237, 2001.

WILKINS, R.J. Some perspectives on grassland and grassland research. In: Jarvis, S.C. (Ed.), Progress in Grassland Science: Achievements and Opportunities. Proceedings of an IGER Research Colloquium, North Wyke, Institute of Grassland and Environmental Research. pp. 68-77, 2000. 